\title{
A comparison of three dose timings of methylprednisolone in infant cardiopulmonary bypass
}

Davinia E Withington ${ }^{1,2^{*}}$, Patricia S Fontela ${ }^{2,3}$, Karen P Harrington ${ }^{4}$, Christo Tchervenkov ${ }^{5}$ and Larry C Lands ${ }^{2}$

\begin{abstract}
Although commonly used in pediatric cardiopulmonary bypass (CPB) optimal dose and timing of steroid administration is unclear. We hypothesized that early administration of a commonly used dose of methylprednisolone given the evening before surgery (ultra-early) would be more effective in decreasing CPB-related inflammatory response than when given at induction of anesthesia (early) or in pump prime (standard).

This was a triple-arm, parallel, active control, superiority RCT including 54 infants $<2$ years old who were randomised to receive $30 \mathrm{mg} / \mathrm{kg}$ methylprednisolone at one of the 3 time points. Outcomes included alveolar-arterial oxygen gradient (AaDO2) during, 24, 48 and 72 hours post-CPB, IL-6, IL-8 and reduced (GSH) to oxidized (GSSG) glutathione ratio (pre-ultrafiltration on CPB, end-CPB and 24 hours), PICU length of stay (LOS) and ventilator days. Data were analysed using descriptive statistics and a random effects regression model.

The ultra-early group had higher Risk Adjusted Congenital Heart Surgery Score, lower age and longer CPB times than the other groups. No significant differences in AaDO2, IL-8, PICU LOS and ventilator days were observed between groups. Compared to the ultra-early group, the overall rise in IL-6 in the early and standard groups was lower, $-27.8 \mathrm{pg} / \mathrm{ml}$ $(95 \% \mathrm{Cl}-52.7,-2.9)$ and $-35.3 \mathrm{pg} / \mathrm{ml}(95 \% \mathrm{Cl}-64.3,-6.34)$, respectively. GSH:GSSG was significantly lower in the standard group $(-35.9 ; 95 \% \mathrm{Cl}-63.31,-8.5)$ at 24 hours post-CPB.

Ultra-early administration of methylprednisolone does not improve AaDO2 post-CPB, nor diminish cytokine release. Lower GSH:GSSG in the standard group suggests less oxidative stress. However despite statistical adjustments conclusions are limited by the unbalanced randomisation of the groups.
\end{abstract}

Keywords: Cardiopulmonary bypass; Pediatric; Methylprednisolone; Inflammatory response; Leukotrienes; Oxidative stress; Oxygenation

\section{Background}

The use of corticosteroids as a means of diminishing the inflammatory response to cardiopulmonary bypass (CPB) has become a standard of practice in many institutions (Jonas 2004). Administration regimens vary since clear evidence of benefit or superiority of a particular timing remains elusive. However the administration of one dose of corticosteroid in pump prime is a standard of practice at many centres and is the preferred timing

\footnotetext{
* Correspondence: davinia.withington@mcgill.ca

'Department of Pediatric Anesthesia, McGill University Health Center/

Montreal Children's Hospital, 2300 Tupper Street, Room C-1118, Montreal,

Quebec, Canada

${ }^{2}$ Department of Pediatrics, McGill University Health Center/Montreal

Children's Hospital, Montreal, Canada

Full list of author information is available at the end of the article
}

described in many studies (Hauser et al. 1998). In a survey of 36 international centres $97 \%$ of respondents used steroids in some cases and of these $83 \%$ used a single dose (Checcia et al. 2005). Since corticosteroids require approximately 2 hours for RNA transcription, and longer for maximal effects, administration in the pump prime may be too late to reduce the inflammatory response triggered by exposure to extracorporeal circulation (Ito et al. 1992; Xu et al. 1995).

Lodge et al. (1999) demonstrated improved alveolararterial oxygen gradient $\left(\mathrm{A}-\mathrm{aDO}_{2}\right)$ and total lung water in neonatal piglets given methylprednisolone 8 hours before $\mathrm{CPB}$ plus in the prime compared to prime alone. Two studies performed in humans investigated the effect of two doses of corticosteroids on CPB-induced 
inflammatory response, one of them given pre-operatively (Schroeder et al. 2003; Graham 2011). However, it remains unclear if the benefits observed in these studies are due to early administration of corticosteroids or use of two doses. Therefore, we performed this study with the objective of testing the hypothesis that a single ultraearly dose of methylprednisolone (the evening preceding surgery (Clarizia et al. 2011)) would improve A-aDO2 and other clinical and biochemical outcome measures compared to early (at anesthesic induction, 1-2 hours pre- $\mathrm{CPB}$ ) or standard (during $\mathrm{CPB}$ ) administration in children aged less than 2 years undergoing corrective congenital cardiac surgery.

\section{Methods}

With approval from the Institutional Review Board of Montreal Children's Hospital $(\mathrm{MCH})$ we conducted a triple-arm, parallel, active control, superiority randomized controlled trial (RCT) with allocation ratio 1:1:1. $\mathrm{MCH}$ is a tertiary care university-affiliated hospital undertaking around 100 cardiac surgery cases requiring $\mathrm{CPB} /$ year.

\section{Patients and protocol}

Patients under two years old scheduled for corrective cardiac surgery via median sternotomy, requiring $\mathrm{CPB}$ with moderate hypothermia, were considered eligible. Exclusion criteria were use of systemic corticosteroids within 3 months of enrolment, pre-existing primary pulmonary or renal pathology, surgery estimated as requiring $<90$ minutes $\mathrm{CPB}$, e.g. secundum atrial septal defect, plan for deep hypothermia and/or circulatory arrest. One cardiac surgeon operated on all patients. Informed consent was obtained from parents at the preoperative visit.

All patients received intravenous methylprednisolone $30 \mathrm{mg} / \mathrm{kg}$ as per institutional practice: ultra-early group (UE) the evening before $\mathrm{CPB}$; early group (E) at anesthesia induction; standard group (S) in the pump prime. Timing of ultra-early doses conformed to known pharmacodynamics of corticosteroids (Ito et al. 1992; Xu et al. 1995). All patients received three intravenous solutions of identical appearance, one at each time point, two being normal saline and one methylprednisolone.

Patients were assigned to treatment group by simple randomization, with ratio 1:1:1, using computer-generated random numbers. $\mathrm{MCH}$ Pharmacy held the treatment allocation list and prepared identical appearing study medications with labeling "Dose 1, 2 or 3" to maintain blinding. All clinicians and research team members were blinded to the patient's study group.

Intravenous induction was employed if an intravenous cannula was in place otherwise inhalational induction with sevoflurane preceded intravenous cannula insertion.
Fentanyl or sufentanil plus pancuronium or rocuronium were used to facilitate intubation then maintenance was with infusions of sufentanil or fentanyl with midazolam plus pancuronium for neuromuscular blockade. Standard continuous monitoring was employed including intraarterial blood pressure and central venous pressure.

Intravenous cefazolin was administered as antibiotic prophylaxis. In cases where the risk of intra- and postoperative bleeding was assessed as high, aprotinin or tranexamic acid were given by infusion throughout the case. All drugs received were noted in the database.

Prior to CPB heparin $400 \mathrm{U} / \mathrm{kg}$ was given to achieve an ACT of $>400$ seconds. Pump prime was with irradiated reconstituted whole blood in infants $<15 \mathrm{~kg}$ and with clear prime in those $\geq 15 \mathrm{~kg}$. Dideco Lilliput ${ }^{\mathrm{tm}}$ oxygenators were used for infants up to $15 \mathrm{~kg}$ and D-905 (Dideco, Markham, Ontario) oxygenators for those $>15 \mathrm{~kg}$. At initiation of CPB furosemide $0.1 \mathrm{mg} / \mathrm{kg}$ and phentolamine $0.1 \mathrm{mg} / \mathrm{kg}$ were given plus the third syringe of study drug. The target hematocrit was $20 \%$. Pump flow was maintained at $2-3 \mathrm{~L} / \mathrm{min} / \mathrm{m}^{2}$ during normothermia with reduction $\mathrm{du}-$ ring cooling as per standard protocol. After aortic crossclamping, cold cardioplegia (St Thomas' Hospital solution) was infused for myocardial protection. Ultrafiltration was continuous throughout $\mathrm{CPB}$.

After rewarming, inotropic support was introduced as necessary prior to separation from CPB. Heparin was reversed 1:1 with protamine sulphate. Blood products were used as needed to maintain a hematocrit of $40 \%$ and to control bleeding.

\section{Outcomes and data collection}

The primary outcome was the $\mathrm{A}-\mathrm{aDO}_{2} 72$ hours after CPB. Our secondary clinical outcomes were 24-, 48-, and 72-hour fluid balance, weight, vasoactive inotrope score (Gaies et al. 2010), and urinary output, duration of mechanical ventilation and PICU length of stay (LOS). Secondary biochemical outcomes were plasma interleukin 6 and 8 (IL-6 and IL-8), and reduced and oxidized glutathione (GSH:GSSG) ratio.

Data were collected by trained research team members. Demographic (age, gender) and clinical information (weight, height, congenital cardiac malformation, $\mathrm{CPB}$ and cross-clamp time, minimal nasopharyngeal temperature during surgery, and Risk Adjusted Congenital Heart Surgery Score [RACHS]) were recorded for all participants.

Baseline blood samples for inflammatory response biomarkers were taken at the same time as routine preoperative blood work. Further samples were taken during CPB (before ultrafiltration), immediately before and 24 hours after $\mathrm{CPB}$ cessation. Plasma for IL- 6 and IL- 8 assays was recovered immediately and frozen at $-70^{\circ} \mathrm{C}$ before batch analysis using BD Biosciences ${ }^{\mathrm{Tu}}$ ELISA kits according to the manufacturers' instructions. 
To evaluate oxidative stress we quantified total and oxidized glutathione in whole blood lysates. A low GSH: GSSG ratio is indicative of oxidative stress. For the measurement of total glutathione, $400 \mu \mathrm{l}$ venous blood were deproteinized with $0.9 \% 5$-sulfosalicylic acid. To measure GSSG, blood specimens were incubated with 9\% 2-vinylpyridine to derivatize GSH prior to deproteinization. Deproteinized supernatants of whole blood were stored at $-80^{\circ} \mathrm{C}$ pending analysis. To quantify glutathione (GSH), samples were diluted and neutralized with $100 \mathrm{mM}$ phosphate buffer $(\mathrm{pH} 7.4)$ containing $5 \mathrm{mM}$ EDTA. GSH analysis was conducted by the method established in our laboratory's previous publications (Dauletbaev et al. 2001).

\section{Statistical methods}

Based on the available evidence of the possible effect of methylprednisolone on $\mathrm{A}-\mathrm{aDO}_{2}$ we defined an $\mathrm{A}-\mathrm{aDO}_{2}$ difference, at 72 hours post-CPB, of $60 \mathrm{mmHg}$ between groups (control and intervention) as clinically significant (Lodge et al. 1999). According to our calculation a sample size of 15 patients per group (total 45 patients) was sufficient to detect these effects at the 2-sided $\alpha$ level of 0.05 and with a power of $80 \%$. We recruited a total of 54 patients to account for dropout.

Data were analyzed using an intention-to-treat approach. We used descriptive statistics, including mean (standard deviation - SD) and median (interquartile range - IQR), as well as frequency distribution, to describe the characteristics of the study groups. Differences in continuous variables were assessed by Student $t$-test; in the case of violation of the normality assumption (non-parametric data), the Mann-Whitney test was used. $P$ values $\leq 0.05$ were considered significant.

Due to the imbalance of RACHS score, CPB and cross-clamp time between groups, the data were also analysed using multivariate logistic and multivariate random effects regression models, which adjusted our results for possible confounding. This also addressed the fact that each patient had repeated measurements of the different variables. Statistical analysis was performed using $\mathrm{R}$ version 2.11.0.

\section{Results}

A total of 54 patients were recruited between 27th June 2001 and 24th April 2007. Participant flow is described in Figure 1. There were 2 protocol violations: 1 ) methylprednisolone $30 \mathrm{mg} / \mathrm{kg}$ was given 8 hours before surgery instead of study dose 1; 2) methylprednisolone $30 \mathrm{mg} / \mathrm{kg}$ was given at induction instead of study dose 2 .

Demographic data are presented in Table 1. UE group patients were significantly younger but not smaller than those in the other groups. Although not statistically significant there was a trend to longer $\mathrm{CPB}$ and cross- clamp times in the UE group. Due to intraoperative changes in surgical plans, 17 (32\%) infants had low flow or hypothermic circulatory arrest. Aprotinin was administered to 8 cases (UE group: 4, E group: 2, S group: 2).

There was no significant difference in $\mathrm{A}-\mathrm{aDO}_{2}$ between the groups at 72 hours post-CPB. Evolution of $\mathrm{A}-\mathrm{aDO}_{2}$ over time is shown in Figure 2. Moreover, the results of the regression models showed no significant differences between groups in any measured clinical variable including fluid balance, urine output, and weight gain. Mean duration of mechanical ventilation was $6.3( \pm 4), 5.65( \pm 4)$ and $4.64( \pm 4)$ days in UE, E and $S$ groups respectively ( $>0.05)$. Similarly, although PICU LOS was on average 2 days less in group $\mathrm{S}$ than the other groups (9.17 vs. 11.24 and 11.82 days, respectively, $\mathrm{p}>0.05$ ), this difference was not significant when logistic regression accounted for the inter-group differences in age, RACHS and CPB time. The inotrope score during the first 72 hours post-surgery was lower in group $S$ compared to the other groups (Table 2). One death occurred in each group.

Inflammatory mediator and glutathione ratio data were collected for 51 patients (94\%). Baseline IL-6 values were higher in group UE $(63.61 \pm 101.36 \mathrm{pg} / \mathrm{ml})$ than group $\mathrm{E}$ $(18.27 \pm 22.42 \mathrm{pg} / \mathrm{ml})$ or group $\mathrm{S}(17.96 \pm 34.16 \mathrm{pg} / \mathrm{ml})$ and rose higher than in these groups (Figure 3 ). All 3 groups had similar baseline IL-8 values with no significant differences between the groups at any time point.

Regarding the evolution of the GSH:GSSG ratio, changes were most marked in group UE, which presented a delayed decrease in comparison to the other groups between ultra-filtration and end-CPB (Figure 4). Group E showed the least change with time with no significant difference between pre-operative and 24 hour post-op values, a different pattern from the other 2 groups which both showed increases from baseline. Furthermore, considering all time-points, overall GSH:GSSG ratio of group S was significantly higher (1179: 95\% CI 25.05, 2332.75) than that of the other 2 groups.

\section{Discussion}

Our findings do not support the hypothesis that a single ultra-early corticosteroid dose, compared to single doses at induction of anesthesia or on $\mathrm{CPB}$, reduces the inflammatory response to CPB.

While there was no statistical difference in A-aDO2 between the groups in the present study, $\mathrm{A}-\mathrm{aDO} 2$ was higher at 6 hours post-CPB in both early groups, and higher at 24 hours post-CPB in the UE group. Our results contradict the findings from previous published studies. However, all the animal and human studies that so far addressed this question (Lodge et al. 1999; Schroeder et al. 2003; Graham 2011; Clarizia et al. 2011) compared the use of double dose of steroids (early + prime) to prime administration only. Our aim was to determine if the 


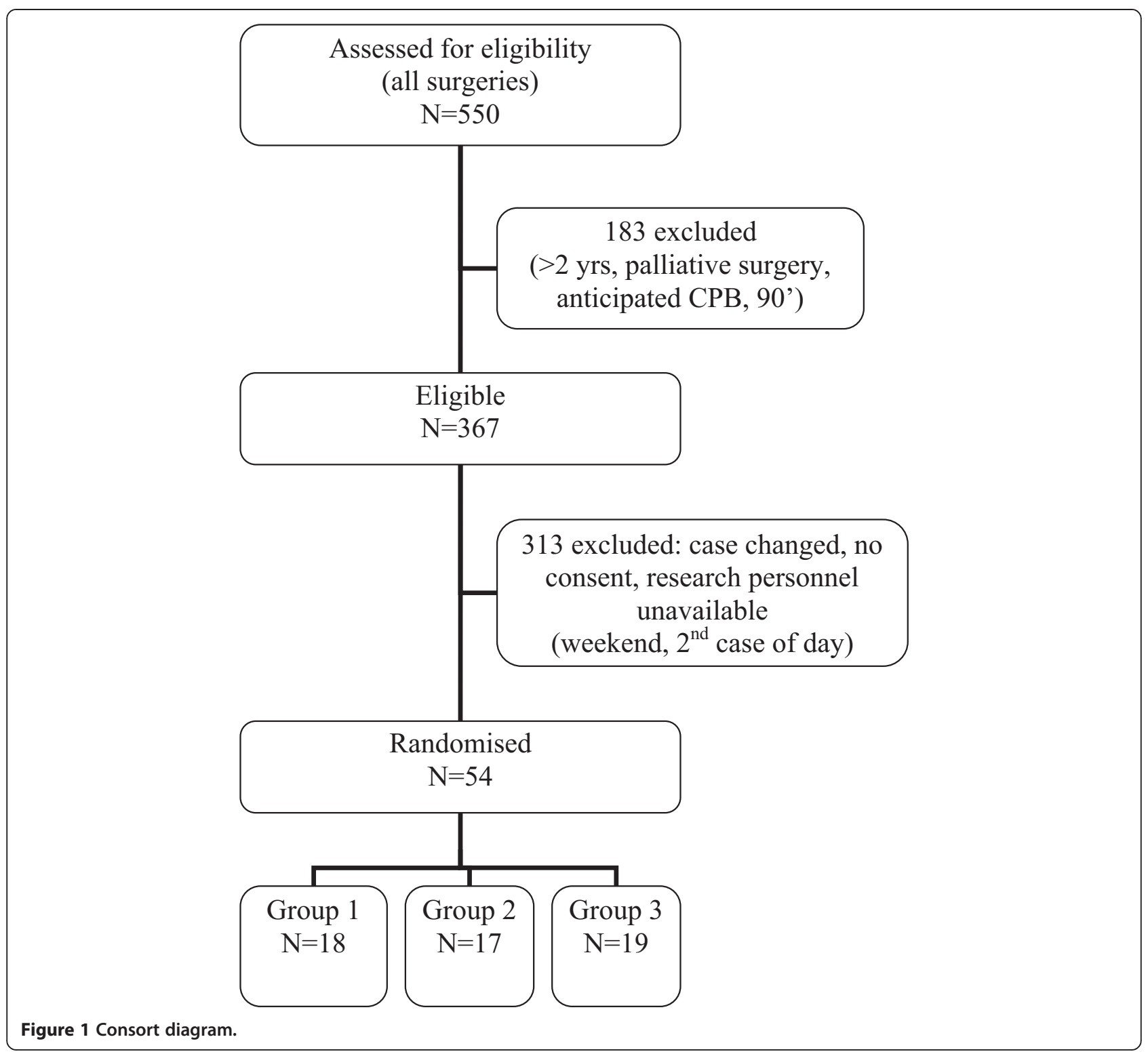

previously described improvements in oxygenation were due to the earlier timing of the first steroid dose or to administration of two doses. The latter would appear to be the case.

The differences demonstrated by Lodge et al. (1999) in piglets were of markedly improved post-operative $\mathrm{A}-\mathrm{aDO}_{2}$ gradient (absolute values not provided; $\mathrm{p}<0.0003$ ), pulmonary hemodynamics $(\mathrm{p}=0.036)$, lung water $(86.4 \% \mathrm{vs}$. $82.9 \% ; \mathrm{p}=0.001)$ and body weight gain (96 g/kg vs. $160 \mathrm{~g} / \mathrm{kg}$; p) in the 8 and 1.5 hour pre-op-double dose corticosteroid group compared to placebo. Those who received methylprednisolone in the prime alone had results intermediate between placebo and the pre-op/ double dose groups.

The retrospective review of Clarizia et al. (2011) also demonstrated better outcomes in infants receiving 2 versus 1 doses of steroid. Similar to the study of Lodge et al. (1999), they observed that patients receiving a single intraoperative dose (30 $\mathrm{mg} / \mathrm{kg}$ methylprednisolone) had outcomes between those receiving two pre-operative doses $(10 \mathrm{mg} / \mathrm{kg}$ on pre-operative evening, $10 \mathrm{mg} / \mathrm{kg}$ 2 hours pre-induction) plus the intraoperative dose and controls (duration of mechanical ventilation 4.4 vs. 3.2 vs. 5 days, respectively; $\mathrm{p}=0.002$ ). The RCT of Schroeder et al. (2003) evaluated the use of an early dose (4 hours pre-CPB) plus a prime dose of steroids in infants versus a single prime dose. They showed improvement in the arterio-venous oxygen gradient at 24 hours, as well as in PICU LOS and incidence of low-cardiac output syndrome (LCOS) in their double-dose group. Finally, Graham (2011) observed lower plasma levels of IL-6 after the preoperative dose of corticosteroids, but no significant 
Table 1 Patient characteristics stratified by study group

\begin{tabular}{|c|c|c|c|}
\hline Variable & Ultra-early group $(n=18)$ & Early group $(n=17)$ & Standard group $(n=19)$ \\
\hline Males (\%) & $10(56)$ & $12(71)$ & $12(63)$ \\
\hline \multicolumn{4}{|l|}{ Age (months) } \\
\hline Mean (SD) & $0.76(0.86)$ & $1.29(2.44)$ & $2.46(3.68)$ \\
\hline Median (IQR) & $0.47(0.26-0.91)$ & $0.33(0.27-1.00)$ & $1.00(0.27-3.97)$ \\
\hline Height (cm, mean, SD) & $51.9(3.12)$ & $52.4(7.68)$ & $55.9(10.46)$ \\
\hline \multicolumn{4}{|l|}{ Pre-surgical weight (kg) } \\
\hline Mean (SD) & $3.73(0.84)$ & $3.65(1.30)$ & $4.60(2.27)$ \\
\hline Median (IQR) & $3.52(3.16-3.96)$ & $3.29(2.94-3.89)$ & $3.96(3.58-5.02)$ \\
\hline \multicolumn{4}{|l|}{$Z$ score (mean) } \\
\hline Weight for length (SD) & $-0.31(1.60)$ & $-0.71(2.01)$ & $-0.57(2.05)$ \\
\hline Weight for age (SD) & $-0.72(1.51)$ & $-1.15(1.29)$ & $-1.53(2.27)$ \\
\hline Cyanosis & $13(72 \%)$ & $12(71 \%)$ & $12(63 \%)$ \\
\hline \multicolumn{4}{|l|}{ Lesion (\%) } \\
\hline Tetralogy of Fallot & $3(17)$ & $5(29)$ & $7(37)$ \\
\hline Transposition of great arteries & $8(44)$ & $7(41)$ & $4(21)$ \\
\hline Ventricular septal defect & 0 & 0 & $1(5)$ \\
\hline Atrioventricular canal & $2(11)$ & $1(6)$ & $2(11)$ \\
\hline Hypoplastic Aorta & 0 & $2(12)$ & 0 \\
\hline Other & $5(28)$ & $2(12)$ & $5(26)$ \\
\hline RACHS (mean, SD) & $3.00(0.49)$ & $3.06(0.56)$ & $2.53(0.61)$ \\
\hline $\mathrm{SatO}_{2} \mathrm{RA}(\%$, mean, SD) & $85.6(8.29)$ & $81.9(13.18)$ & $89.4(8.76)$ \\
\hline \multicolumn{4}{|l|}{ CPB time (min) } \\
\hline Mean (SD) & $231(234)$ & $256(386)$ & $155.4(81)$ \\
\hline Median (IQR) & $169(136-221)$ & $172(146-202)$ & $133.0(108-159)$ \\
\hline \multicolumn{4}{|l|}{ Aortic cross-clamp time (min) } \\
\hline Mean (SD) & $98(36)$ & $97(30)$ & $81(36)$ \\
\hline Median (IQR) & $88(75-123)$ & $97(86-108)$ & $75(52-90)$ \\
\hline Nasopharyngeal temperature $\left({ }^{\circ} \mathrm{C}\right.$, mean, SD) & $22.4(3.47)$ & $20.5(2.93)$ & $23.8(3.78)$ \\
\hline Open chest (\%) & $10(56 \%)$ & $10(59 \%)$ & $4(26 \%)$ \\
\hline
\end{tabular}

$\mathrm{SD}=$ standard deviation; $\mathrm{IQR}=$ interquartile range); $\mathrm{RACHS}=$ Risk Adjusted Congenital Heart Surgery Score; $\mathrm{SatO}_{2} \mathrm{RA}=$ oxygen saturation on room air; $\mathrm{CPB}=$ cardiopulmonary bypass.

difference in the incidence of LCOS between neonates who received methylprednisolone in the pump prime only and those who also had a dose 8 hours pre-CPB and in the prime. Renal function was worse in the double-dose group.

Oxidative stress has rarely been studied in pediatric CPB. Two animal studies have shown increased tissue anti-oxidant activity after methylprednisolone given 24 hours to 5 days pre-CPB (Valen et al. 2000a, b). Christen et al. noted that oxidative stress preceded the peak in the inflammatory response (Christen et al. 2005). It is interesting to note in the present study that the whole blood GSH:GSSG ratio was highest in the S group, suggesting less oxidative stress. Further, this ratio was low pre-operatively and during $\mathrm{CPB}$, rising afterwards, compatible with oxidative stress occurring early on during $\mathrm{CPB}$.

Our baseline levels of IL-6 and IL-8 are significantly higher than those described by some pediatric cardiac studies, where mean values range from zero to $20 \mathrm{pg} / \mathrm{ml}$ (Schroeder et al. 2003; Graham 2011; Christen et al. 2005; Ashraf et al. 1997a), however others (Jonas 2004) have quoted much higher baseline values $(\sim 200 \mathrm{pg} / \mathrm{ml})$. Our higher levels from baseline sampling the day before surgery may be related to a sicker population some of whom had undergone atrial septostomies. However the 


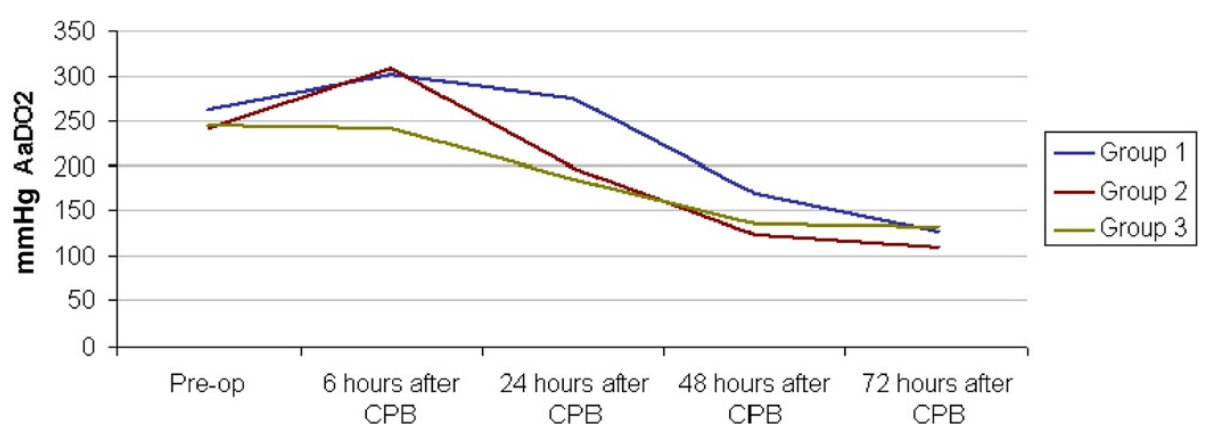

Figure 2 Evolution of mean $\mathrm{A}-\mathrm{aDO}_{2}$ over time stratified by study group.

peak values that we obtained are similar or smaller in magnitude to those reported by multiple studies (Hauser et al. 1998; Schroeder et al. 2003; Santos et al. 2007).

The cytokine pattern differed between the three groups. IL-6 rose rapidly in the UE and S groups following the end of $\mathrm{CPB}$, while the $\mathrm{E}$ group rose during $\mathrm{CPB}$, and continued rising afterwards. All three groups had a rise in IL-8 during and following CPB. This is compatible with the work of Christen et al. (2005) in humans showing that the inflammatory response lagged behind oxidative stress as measured by ascorbate and malondialdehyde. It is important to highlight that the rise in IL-8 was less in the S group compared to the UE and E groups which may be due to less oxidative stress in this group.

Modification of cytokine release during pediatric $\mathrm{CPB}$ has been attempted by a variety of physical and biochemical methods (Allan et al. 2010; Ashraf et al. 1997b; Horton et al. 1999; Finn et al. 1996; Gessler et al. 2005; Sekido et al. 1993). These strategies have been largely unsuccessful and expensive. Corticosteroids have the

Table 2 Clinical outcomes stratified by study group

\begin{tabular}{|c|c|c|c|c|}
\hline Variable (mean) & Ultra-early group $(n=18)$ & Early group $(n=17)$ & Standard group $(n=19)$ & $\mathrm{p}^{*}$ \\
\hline \multicolumn{5}{|l|}{ Weight (kg) } \\
\hline Pre-operative (SD) & $3.73(0.84)$ & $3.65(1.30)$ & $4.60(2.27)$ & $>0.05$ \\
\hline 24 hours after surgery (SD) & $4.20(0.85)$ & $4.23(1.65)$ & $4.74(1.91)$ & $>0.05$ \\
\hline 48 hours after surgery (SD) & $4.15(0.85)$ & $4.10(1.47)$ & $5.10(2.11)$ & $>0.05$ \\
\hline 72 hours after surgery (SD) & $4.00(0.87)$ & $3.94(1.36)$ & $5.06(2.11)$ & $>0.05$ \\
\hline \multicolumn{5}{|l|}{ Urinary output $(\mathrm{ml} / \mathrm{kg} / \mathrm{h})$} \\
\hline 24 hours (SD) & $1.47(0.64)$ & $1.27(0.62)$ & $1.36(0.68)$ & $>0.05$ \\
\hline 48 hours (SD) & $4.41(1.47)$ & $4.58(1.73)$ & $3.43(1.32)$ & $0.047^{\delta}$ and $0.037^{\psi}$ \\
\hline 72 hours (SD) & $5.24(1.69)$ & $5.56(2.08)$ & $4.71(1.31)$ & $>0.05$ \\
\hline \multicolumn{5}{|l|}{ Balance (ml/kg/day) } \\
\hline 24 hours (SD) & $61.47(39.48)$ & $46.50(40.36)$ & $57.13(70.43)$ & $>0.05$ \\
\hline 48 hours (SD) & $-34.66(47.60)$ & $-33.94(48.73)$ & $-11.63(35.40)$ & $>0.05$ \\
\hline 72 hours (SD) & $-54.53(47.80)$ & $-53.50(44.55)$ & $-36.28(31.20)$ & $>0.05$ \\
\hline \multicolumn{5}{|l|}{ Inotrope score } \\
\hline 24 hours (SD) & $16.41(6.39)$ & $13.96(14.86)$ & $11.81(25.11)$ & $>0.05$ \\
\hline 48 hours (SD) & $17.71(6.23)$ & $13.12(10.27)$ & $9.25(24.68)$ & $>0.05$ \\
\hline 72 hours (SD) & $18.33(5.05)$ & $15.66(6.83)$ & $13.80(24.58)$ & $>0.05$ \\
\hline MV duration (days, SD) & $6.30(3.51)$ & $5.65(4.18)$ & $4.94(3.62)$ & $>0.05$ \\
\hline PICU LOS (days, SD) & $11.82(11.77)$ & $11.24(9.10)$ & $9.17(5.65)$ & $>0.05$ \\
\hline Death (\%) & $1(0.06)$ & $1(0.06)$ & $1(1.19)$ & $>0.05$ \\
\hline
\end{tabular}

$\mathrm{SD}=$ standard deviation, $\mathrm{MV}=$ mechanical ventilation, PICU LOS = pediatric intensive care unit length of stay.

${ }^{*}$ Comparison between study groups (UE vs. S, UE vs. E, and E vs. S).

${ }^{\delta}$ Comparison between UE and S groups.

${ }^{\psi}$ Comparison between $\mathrm{E}$ and $\mathrm{S}$ groups. 


\section{II-6}

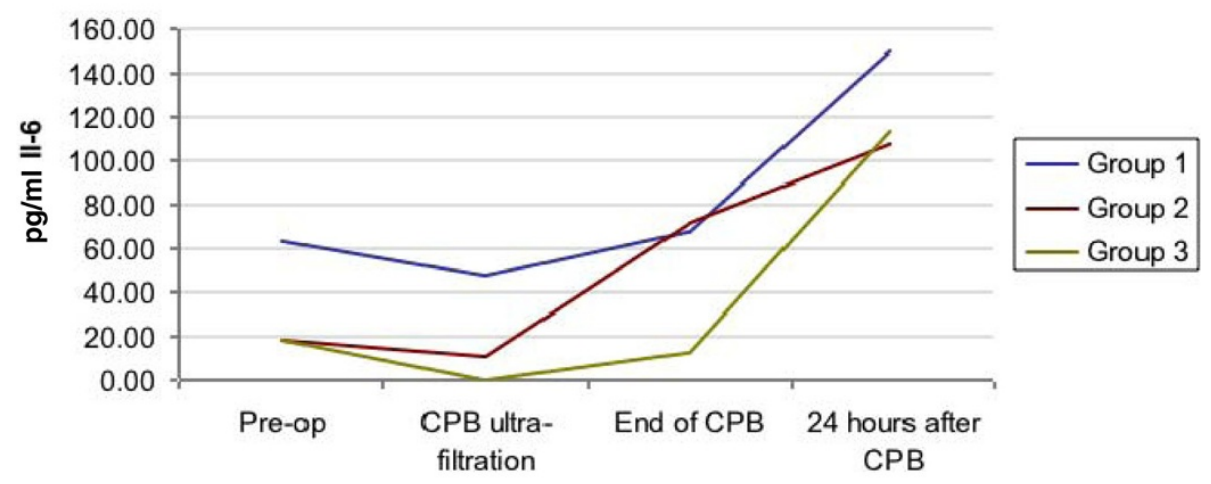

$\|-8$

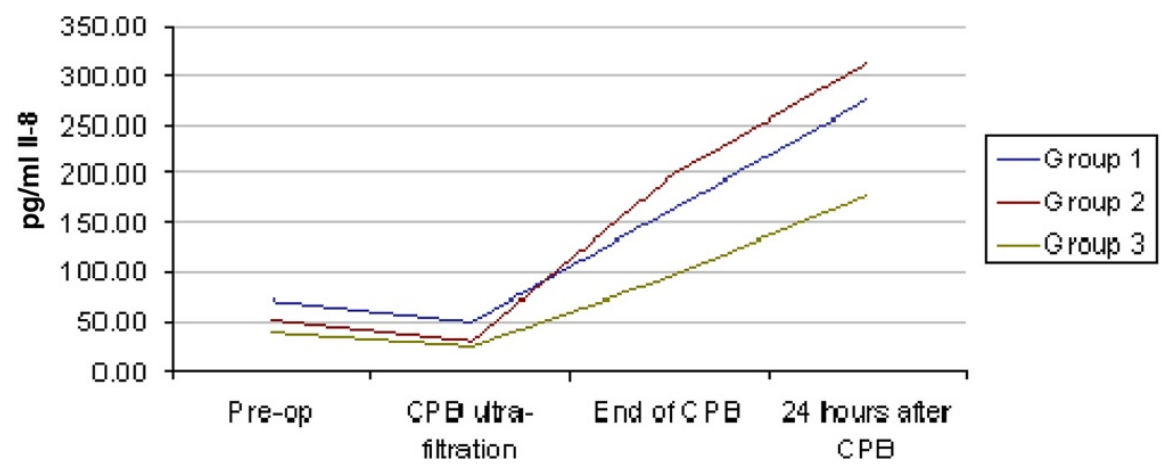

Figure 3 Evolution of mean IL- 6 and IL-8 over time stratified by study group.

advantage of being inexpensive, widely available and have been employed to attenuate the inflammatory response to CPB for decades. Schroeder et al. (Schroeder et al. 2003) showed that the plasma levels of IL-6 were lower by the end of $\mathrm{CPB}$ in the double-dose group $(\mathrm{p}<0.05)$, but IL-6 values at 24 hours did not differ between the groups. Graham (2011) reported that the use of a double dose of corticosteroids reduces pre-operative IL-6, but both double-dose and at prime groups had a similar pattern and magnitude of increase in IL-6 in the first 24 hours post-operatively. However improvement in clinical outcomes remains the primary goal and has not been uniformly correlated with changes in cytokine release (Graham 2011; Keski-Nisula et al. 2013).

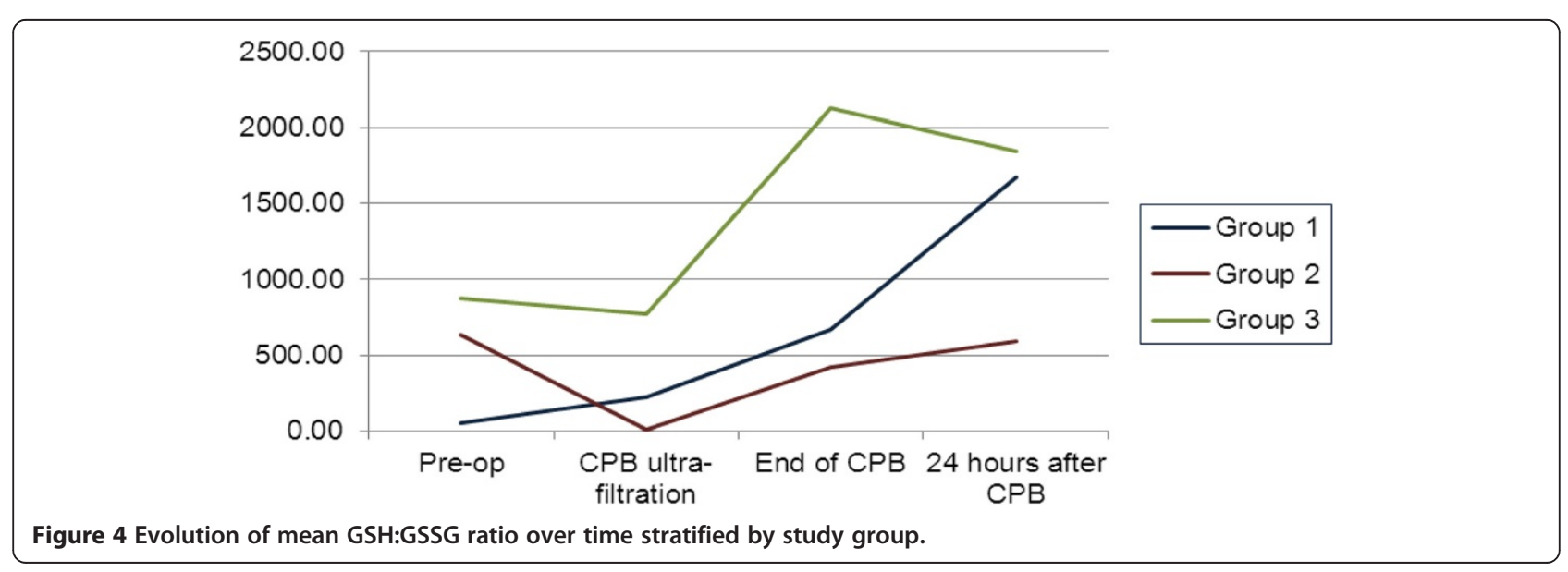


Because none of the studies discussed above used a single early dose of corticosteroids as their intervention, it is possible that the positive results shown by them (Lodge et al. 1999; Schroeder et al. 2003; Graham 2011; Clarizia et al. 2011) are due to the administration of two doses of steroids and not to their early administration, which left the question regarding the effect of timing unanswered. Our study is the first to compare different timings of one corticosteroid dose alone.

The main limitation of our study is the unbalanced randomisation of our cases with respect to age and complexity of cardiac disease (RACHS). Nevertheless, the use of random effects models allowed adjustment for these variables and also accounted for repeated measures of different variables per patient. Moreover, although the RACHS was statistically significantly different, a review of the actual lesions along with $\mathrm{CPB}$ and cross-clamp times reveal very little difference between the ultra-early and early groups, despite which the former group spent longer times ventilated and on the PICU. Our sample size calculation was based on Lodge et al., who demonstrated a very large difference between groups (Lodge et al. 1999). However, if this difference is actually smaller, we were underpowered to observe it. In addition, due to the small number of cases who received aprotinin, we could not evaluate its effect as a modulator of cytokine release during CPB. Some authors have also suggested a modulating effect of tranexamic acid on inflammatory response however this appears to be much less than that of aprotinin and has not been clearly demonstrated in infants (Graham et al. 2012; Later et al. 2009). Finally, this was a single institution study, which lead to a long duration of recruitment. However there were no major changes in anesthesic technique, management of $\mathrm{CPB}$ or post-operative care during this period and the same surgeon performed all the operations.

\section{Conclusions}

In conclusion we observed that the timing of a sin gle methylprednisolone dose alters neither $\mathrm{AaDO}_{2}$ at 72 hours nor clinical variables, including duration of mechanical ventilation in infants undergoing corrective congenital heart surgery. While standard clinical parameters did not differ between the groups, the standard group required less inotropic support, had a shorter length of stay, and less oxidation of glutathione. Generally the ultra-early group had more evidence of inflammation and oxidative stress. Although this group were younger and had higher RACHS Scores statistical analysis of the results suggest that the standard approach of administering corticosteroids at the start of bypass, rather than prior to surgery, may be the better approach. A larger multi-centered study is required to verify these findings.

\section{Competing interests}

The authors have no competing interests to declare.

\section{Authors' contributions}

DEW was involved in study concept, design and conduct, data interpretation, writing and coordinating drafts of the manuscript and revising it critically and approving the version to be published. PSF contributed to data acquisition, designed and carried out the data analysis plan and contributed to interpretation of the analysis and to writing the manuscript and its final approval. KPH contributed to data acquisition. LCL was involved in study concept and design, assisted in interpretation of the data analysis and contributed to writing and approved the final manuscript version. $\subset T$ contributed to study concept and design and edited and approved the final manuscript version. All authors read and approved the final manuscript.

\section{Acknowledgements}

We wish to acknowledge the help of Mr. Christos Calaritis, perfusionist, for aid in collection of intra-operative samples, Mr. Nurlan Dauvet and Mr. Brian Meehan, laboratory technicians for assistance in processing and storing samples. Dr. Jose Martinez and Mme. Josée Gaudreault assisted with patient recruitment. Ms. Roula Cacolyris assisted with manuscript preparation. This study was made possible by grants from the Canadian

Anesthesiologists' Society Research Fund (Earl Wynands Research Award in Cardiovascular Anesthesia) and from the Quebec Heart and Stroke Foundation. In addition through the Heart and Stroke Foundation it received the Club Lions de Buckingham en mémoire de Robert Champagne Award.

\section{Author details}

${ }^{1}$ Department of Pediatric Anesthesia, McGill University Health Center/ Montreal Children's Hospital, 2300 Tupper Street, Room C-1118, Montreal, Quebec, Canada. Department of Pediatrics, McGill University Health Center/ Montreal Children's Hospital, Montreal, Canada. ${ }^{3}$ Department of Epidemiology, Biostatistics, and Occupational Health, McGill University Montreal, Montreal, Canada. ${ }^{4}$ Department of Critical Care, Centre Hospitalier Universitaire Ste Justine, Montreal, Canada. ${ }^{5}$ Division of Pediatric Cardiothoracic Surgery, McGill University Health Center/Montreal Children's Hospital, Montreal, Canada.

Received: 25 July 2014 Accepted: 15 August 2014

Published: 29 August 2014

\section{References}

Allan CK, Newburger JW, McGrath E, Elder J, Psoinos C, Laussen PC, del Nido PJ, Wypij D, McGowan FX Jr (2010) The relationship between inflammatory activation and clinical outcome after infant cardiopulmonary bypass. Anesth Analg 111:1244-1251

Ashraf SS, Tian Y, Zacharrias S, Cowan D, Martin P, Watterson K (1997a) Effects of cardiopulmonary bypass on neonatal and pediatric inflammatory profiles. Eur J Cardiothorac Surg 12:862-868

Ashraf SS, Tian Y, Cowan D, Shaikh R, Parsloe M, Martin P, Watterson KG (1997b) Proinflammatory cytokine release during pediatric cardiopulmonary bypass: influence of centrifugal and roller pumps. J Cardiothor Vasc An 11:718-722

Checcia PA, Bronicki RA, Costello JM, Nelson DP (2005) Steroid use before pediatric cardiac operations using cardiopulmonary bypass: an international survey of 36 centers. Pediatr Crit Care Med 6:441-444

Christen S, Finckh B, Lykkesfeldt J, Gessler P, Frese-Schaper M, Nielsen P, Schmid ER, Schmitt B (2005) Oxidative stress precedes peak systemic inflammatory response in pediatric patients undergoing cardiopulmonary bypass operation. Free Radic Biol Med 38:1323-1332

Clarizia NA, Manlhiot C, Schwartz SM, Sivarajan VB, Maratta R, Holtby HM, Gruenwald CE, Caldarone CA, Van Arsdell GS, McCrindle BW (2011) Improved outcomes associated with intraoperative steroid use in high-risk pediatric cardiac surgery. Ann Thorac Surg 91(4):1222-1227

Dauletbaev N, Rickmann J, Viel K, Buhl R, Wagner TO, Bargon J (2001) Glutathione in induced sputum of healthy individuals and patients with asthma. Thorax 56:13-18

Finn A, Morgan BP, Rebuck N, Klein N, Rogers CA, Hibbs M, Elliott M, Shore DF, Evans TW, Strobel S, Moat N (1996) Effects of inhibition of complement activation using recombinant soluble complement receptor 1 on neutrophil CD11b/CD18 and L-selectin expression and release of interleukins- 8 and elastase in simulated cardiopulmonary bypass. J Cardiothor Vasc An 111:451-459 
Gaies MG, Gurney JG, Yen AH, Napoli ML, Gajarski R, Ohye RG, Charpie JR, Hirsch JC (2010) Vasoactive-inotropic score as a predictor of morbidity and mortality in infants after cardiopulmonary bypass. Ped Crit Care Med 11(2):234-238

Gessler P, Hohl V, Carrel T, Pfenninger J, Schmid ER, Baenziger O, Prètre R (2005) Administration of steroids in pediatric cardiac surgery: impact on clinical outcome and systemic inflammatory response. Pediatr Cardiol 26:595-600

Graham E (2011) Standardized preoperative corticosteroid treatment in neonates undergoing cardiac surgery: results from a randomized trial. J Thorac Cardiovasc Surg 142:1523-1529

Graham EM, Atz AM, Gillis J, DeSantis SM, Haney AL, Deardorff RL, Uber WE, Reeves ST, McGowan FX, Bradley SM, Spinale FG (2012) Differential effects of aprotinin and tranexamic acid on outcomes and cytokine profiles in neonates undergoing cardiac surgery. J Thorac Cardiovasc Surg 143(5):1069-1076

Hauser GJ, Ben-Ari J, Colvin MP, Dalton HJ, Hertzog JH, Bearb M, Hopkins RA, Walker SM (1998) Interleukin 6 levels in serum and lung lavage fluid of children undergoing open heart surgery correlate with postoperative morbidity Intens Care Med 24:481-486

Horton SB, Butt WW, Mullaly RJ, Thuys CA, O'Connor EB, Byron K, Cockrane AD, Brizard CP, Karl TR (1999) IL-6 and IL-8 levels after cardiopulmonary bypass are not affected by surface coating. Ann Thorac Surg 68:1751-1755

Ito S, Kusunoki Y, Oka T, Ito Y, Okuno A, Yoshioka H (1992) Pharmacokinetics of high-dose methyl-prednisolone in children. Dev Pharmacol Ther 19:99-105

Jonas RA (2004) Comprehensive surgical management of congenital heart disease. Hodder Arnold Publication, London UK, p 147

Keski-Nisula J, Pesonen E, Olkkola KT, Peltola K, Neuvonen PJ, Tuominen N, Sairanen H, Andersson S, Suominen PK (2013) Methylprednisolone in neonatal cardiac surgery: reduced inflammation without improved clinical outcome. Ann Thorac Surg 95(6):2126-2132

Later AFL, Maas JJ, Engbers FHM, Versteegh MIM, Bruggermans EF, Dion RAE, Klautz RJM (2009) Tranexamic acid and aprotinin in low- and intermediate-risk cardiac surgery: a non-sponsored double-blind, randomised, placebo-controlled trial. Eur J Cardiothorac Surg 36:322-329

Lodge AJ, Chai PJ, Daggett CW, Ungerleider RM, Jaggers J (1999) Methylprednisolone reduces the inflammatory response to cardiopulmonary bypass in neonatal piglets: timing of dose is important. J Thorac Cardiovasc Surg 117:515-522

Santos AR, Heidemann SM, Walters HL III, Delius RE (2007) Effect of inhaled corticosteroid on pulmonary injury and inflammatory mediator production after cardiopulmonary bypass in children. Pediatr Crit Care Med 8:465-469

Schroeder VA, Pearl JM, Schwartz SM, Shanley TP, Manning PB, Nelson DP (2003) Combined steroid treatment for congenital heart surgery improves oxygen delivery and reduces post bypass inflammatory mediator expression. Circulation 107:2823-2828

Sekido N, Mukido N, Harada A, Nakanishi I, Watanabe Y, Matsushima K (1993) Prevention of lung reperfusion injury in rabbits by monoclonal antibody against interleukins-8. Nature 365:654-657

Valen G, Kawamaki T, Tähepôld P, Starkopf J, Kairane C, Dumitrescu A, Löwbeer C, Zilmer M, Vaage J (2000a) Pretreatment with methylprednisolone protects the isolated rat heart against ischaemic and oxidative damage. Free Radic Res 33:31-43

Valen G, Kawakami T, Tähepôld P, Dumitrescu A, Löwbeer C, Vaage J (2000b) Glucocorticoid pretreatment protects cardiac function and induces cardiac heat shock protein 72. Am J Physiol 279:H836-H843

Xu ZX, Viviano CJ, Rooney SA (1995) Glucocorticoid stimulation of fatty-acid synthase gene transcription in fetal lung: antagonism by retinoic acid. Am J Physiol 268:L683-L690

doi:10.1186/2193-1801-3-484

Cite this article as: Withington et al:: A comparison of three dose timings of methylprednisolone in infant cardiopulmonary bypass. SpringerPlus 2014 3:484

\section{Submit your manuscript to a SpringerOpen ${ }^{\circ}$ journal and benefit from:}

- Convenient online submission

- Rigorous peer review

- Immediate publication on acceptance

- Open access: articles freely available online

- High visibility within the field

- Retaining the copyright to your article

Submit your next manuscript at $>$ springeropen.com 